\title{
A MULTI-CRITERIA DECISION SUPPORT SYSTEM IN THE ANALYSIS OF FLOOD RISK AND VULNERABILITY MAPPING IN SULEJA, NIGER STATE, NIGERIA
}

\author{
N. K. UMAR ${ }^{1}$, H. S. ABDULLAHI ${ }^{2 *}$ and A. K. USMAN ${ }^{3}$ \\ ${ }^{1}$ Ministry of Education Science \& Technology, Jigawa State, Nigeria \\ 2*Department of Geomatics, Faculty of Environmental Design, Ahmadu Bello University, Zaria, Nigeria \\ ${ }^{3}$ Department of Geography and Environmental management, Faculty of Science, Ahmadu Bello University, Zaria, Nigeria \\ *Corresponding Author: H.S. Abdullahi, Email: haldiya2000a@rocketmail.com,Tel:+2348127749944
}

\begin{abstract}
This study aims at assessing flood risk factors and mapping areas vulnerable to flood in Suleja of Niger State, Nigeria, using Geo-spatial techniques. The method follows a multi-parametric approach and integrates some of the flood causative factors as: rainfall distribution, elevation and slope, drainage network and density, landuse/land-cover and soil type. The Spatial Multi-Criteria Analysis (MCA) was used to rank and display potential locations, while the Analytical Hierarchy Process (AHP) method was employed using pair-wise comparison to compute the priority weights of each factor. The various layers were integrated in weighted overlay tool in ArcGIS to generate the final vulnerability map (high, moderate and low). The normalized criterion weights were obtained for each factor, and the results shows that, rainfall (34) and slope (31) have the highest influence on flood in the study area. The Consistency Ratio (CR) with an acceptable level of 0.05 was obtained which further validated the strength of the judgement. The factor weights from the AHP were incorporated to produce a Geo-hazard map and it showed that areas that are high vulnerable to flood in Suleja constitute about $37 \%$, while moderate and low vulnerable areas constitute about $45 \%$ and $18 \%$ respectively. Elements at high risk of flood are those found at the extreme northeast, where elevation is very low, southwest where rainfall distribution is high and on low lying areas along the depressions. Therefore using the Geo-hazard map as a guide, local councils and other stakeholders can act to prepare for potential floods.
\end{abstract}

Keywords: Flood, Geo-hazard, Mapping, Risk-factors, Vulnerability

\section{Introduction}

Floods are among the most recurring and devastating natural hazards, which result from a number of basic causes of which the most frequent are climatological in nature, but very often induced by anthropogenic interference (Few et al., 2004). Flood occurs when there is an inundation of any area which is not normally covered with water, through a temporary rise in the level of lake, river or sea, and when excess precipitation exceed natural evaporation, infiltration and possible transmission (United Nations International Strategy for Disaster ReductionUNISDR, 2015). Variety of climatic (such as: intense and/or long-lasting precipitation, snow melt etc.) and non-climatic processes (such as elevation, soil character, slope orientation, urbanization etc.) influence flood processes, resulting in flash, urban, river, glacial lake outburst and coastal floods (Wisner et al., 2012).

The high vulnerable potential of floods may be related to the rapid incidence of floods and the spatial dispersal of the areas which may be impacted by these floods. Therefore, the ability to issue timely flood warnings is limited by both the characteristics. However, due to higher generated runoff and less concentration in urban areas, small streams can also rise rapidly after heavy rain (Ozcan and Musaoglu, 2010). Changes in storm intensity and in the urban area produce higher flows that exceed the small culvert's capacity under roads designed for nonurbanized areas. Although when designed, such structures can be adequate but, their capacity may turn out to be poor and thereby cause overflows, creating new water ways and flood the built up areas. In developing countries, lack of maintenance of the drainage channels, and debris and solid waste disposal into such drainage systems may accentuate the situation (Associated Programme on Flood Management-APFM, 2012). The rainfall runoff process, however, is highly complex, non-linear and spatio-temporally varying due to the variability of the terrain and climate characteristics (Chang and Guo, 2006).

In Nigerian context, flood events are influenced by a range of factors including: the overflow of the numerous rivers that transverse the country, unprecedented rainfall amounts and intensity, dam breaks and levee failure, the insufficient drainage systems, urbanization and the underutilization of dams in some parts of the country (Emmanuel, Olawumi and Durojaye, 2012). Suleja among other 
locations lies on the valley of "River Gorges" and characterized by many first order streams which drains directly into River Niger. Communities along the floodplain and surrounding land are affected by floods, which in some years cause considerable damage to their crops and houses. The flood event of 2005, 2012 and 2016 led to the death of hundreds of people. It also brought about the collapse of roads that links the north to the southern FCT axis (Niger State Emergency Management Agency as cited in Vanguard, 2018). The current trend and future scenarios of flood risks therefore demand for accurate spatial information on the potential hazards and risks of floods. Thus, to provide the basis for the development of flood risk management plan by integrating different interests, potential and conflicts over space and land use. Geo-hazard maps need to be created and effectively communicated to various target groups such as decision makers, emergency response units and the public (Yahaya and Abdalla, 2010). The aim of this study is to assess flood risk factors and map areas that are vulnerable to flood in Suleja of Niger State, Nigeria.

\section{Study Area}

Suleja lies between Latitude $9^{\circ} 10^{\prime} 15^{\prime \prime}$ and $9^{\circ} 12^{\prime} 1.17^{\prime \prime} \mathrm{N}$ of equator and Longitude $7^{\circ} 10^{\prime} 20.25^{\prime \prime}$ and $7^{\circ} 11^{\prime} 40.05^{\prime \prime} \mathrm{E}$ of Greenwich meridian (Fig. 1). It covers a land area of $136.33 \mathrm{~km}^{2}$ and had a population of 216,578 (NPC, 2006). The area has gentle rock and the soils are derived from geological parent materials developed on sand stone formations. The soils are usually deep, red and enriched with clay sub-soil (Niger State Bureau of Statistics, 2011; Aminu, et al., 2013). Suleja has tropical climate with an average annual temperature of $26.3{ }^{\circ} \mathrm{C}$ and the average rainfall is $1405 \mathrm{~mm}$. The driest month is December. The highest precipitation occurs in September; with an average of $272 \mathrm{~mm}$. March is the warmest month of the year with average temperature of $29.0{ }^{\circ} \mathrm{C}$. The lowest average temperature is in August at $24.5^{\circ} \mathrm{C}$ (Aminu, et al., 2013).

\section{Methodology}

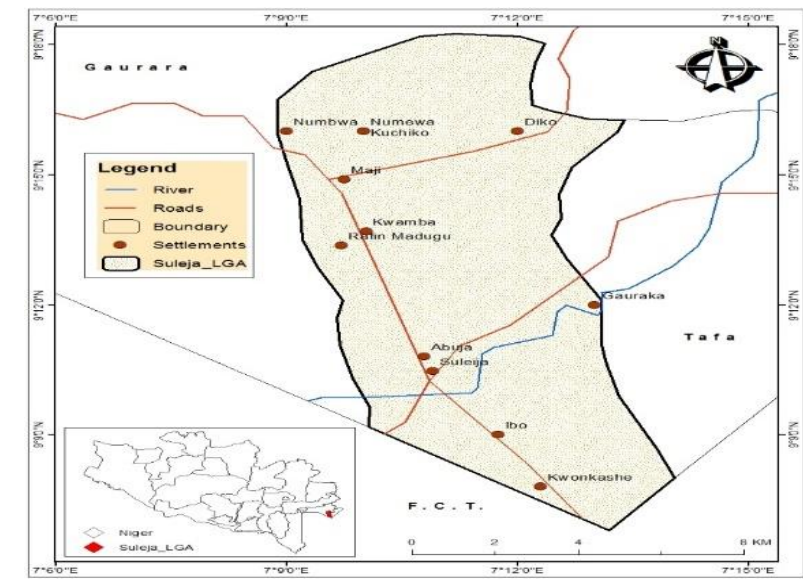

Figure 1: The Study Area (Source: Topographic/Administrative Maps)

\subsection{Types and Sources of Data}

Table 1: Types of Data, Sources and Date of Production

\begin{tabular}{llll}
\hline Data Type & Resolution/Scale & Source & Date \\
\hline SPOT 7 Imagery & $1 \mathrm{~m}$ & SPOT 7 & 2017 \\
Topographic map & $1: 100,000$ & State Ministry of Lands and Survey, Suleja & 2014 \\
Soil Map & $1: 650.000$ & $\begin{array}{l}\text { Department of Geography and Environmental } \\
\text { management, ABU, Zaria }\end{array}$ & 2017 \\
Rainfall data & 20 years (1997-2017) & River Basin Development Authority, Niger & 2017 \\
ASTER data & $30 \mathrm{~m}$ & United States Geological Survey (USGS) & 2018 \\
\hline
\end{tabular}

Source: Author's Computation, 2019

\subsection{Data Processing}

The SPOT 7 and ASTER data were imported in to ArcGIS and geo-referenced. This was followed by subsetting, to obtain the Area of Interest (AOI). Unsupervised classification was performed on the Spot Imagery in order to have a general idea of the area which was followed by object based supervised classification method in ArcGIS for the final Land Use Land Cover (LULC) map. The image was classified based on 'Classification Scheme' of Anderson, Hardy, Roach and Witner (2001). The ASTER data was used to generate the Digital Elevation Model (DEM) of Suleja with the help of the Spatial Analyst tool. 
ASTER data was further subjected to spatial analysis using the 3D spatial analyst tool to generate the Slope map of the area. The topographic map of Suleja and the Soil map of Nigeria were imported into ArcGIS and geo-referenced based on the spatial reference of the other layers. The study area was clipped from the map and digitized, the drainages were also extracted.. Thereafter, the Kernel density tool was employed to drive the drainage density map. Different soil types of the study area were digitized into polygons from the clipped Soil map. Further, the mean annual rainfall for the 20 years was used to create rainfall map of the study area by interpolating the figures using "Kriging". All data layers derived were converted to raster data sets having the same pixel size.

\subsection{Method of Data Analysis}

The relationship between the six thematic layers and their various attributes were derived under the Analytical hierarchy process (AHP) which is utilized usually to determine the relative importance of the criteria in a specified Multi-Criteria decision-making problem (Yalcin and Akyurek, 2004). The procedure by which the weights are produced followed the logic developed by Saaty (1980). Pair-wise comparison of the flood risk factors was performed and results was put into a comparison matrix based on Saaty's fundamental scale. The matrix was populated with values from 1-9 and fractions from $1 / 9$ to $1 / 3$ representing importance of one factor against another in the pair. The values in the matrix need to be consistent, which means that if $\mathrm{x}$ is compared to $\mathrm{y}$, it receives a score of 9 (extreme importance), $\mathrm{y}$ to $\mathrm{x}$ should score 1/9 (little importance). Something compared to itself gets the score of 1 (equal importance). The weights calculated from each column was summed and every element in the matrix was divided by the sum of the respective column. The consistency ratio (CR) was also calculated in order to ensure that the comparison of criteria made by decision makers is consistent. The rule is that a CR less than or equal to 0.10 signifies an acceptable reciprocal matrix, whereas greater than 0.10 is not acceptable (Equation 1). Reclassification of the layers was done into appropriate classes using AHP into the inverse ranking system on a scale of 1 to $\mathrm{n}^{\text {th }}$ values, where 1 represent very low and $\mathrm{n}^{\text {th }}$ very high for rainfall, drainage, elevation, slope and LULC. For soil, 1 denotes poor drain and $\mathrm{n}^{\text {th }}$ well drain soils. All the weighted data sets were integrated in ArcGIS 10.3 to produce the flood vulnerability map by weighted overlay where each class individual's weight was multiplied by the map scores and the results added (Equation 2). The consistency ratio $\mathrm{CR}$ is denoted as;

$$
C R=\frac{C I}{R I}
$$

Where: CI- represents Consistency Index which reflects the consistency of one's judgment

$$
C I=\frac{\lambda_{\max }-n}{1-n}
$$

$\lambda$ is calculated by averaging the value of the consistency vector (factor weight) RI- denotes Random Inconsistency index that is dependent on the sample size (Table 2)

$$
S=\sum w_{i} x_{i}
$$

Where: $\mathrm{S}=$ Vulnerability

$\mathrm{w}_{i}=$ Weight for each map

$\mathrm{x}_{i}=$ Individual map

Table 2: Random Inconsistency Indices (RI) for $\mathrm{n}$ to 10

\begin{tabular}{llllllllllll}
\hline $\mathbf{n}$ value & $\mathbf{1}$ & $\mathbf{2}$ & $\mathbf{3}$ & $\mathbf{4}$ & $\mathbf{5}$ & $\mathbf{6}$ & $\mathbf{7}$ & $\mathbf{8}$ & $\mathbf{9}$ & $\mathbf{1 0}$ \\
\hline $\mathrm{RI}$ & 0 & 0 & 0.58 & 0.89 & 1.12 & 1.24 & 1.32 & 1.41 & 1.45 & 1.49 \\
\hline Source: Adapted from Saaty (1980) & & & & & & &
\end{tabular}

\section{Results and Discussion}

\subsection{Characteristics of Flood Risk Factors in Suleja}

Fig. 2 represents the characteristics of flood risk factors in the study area. From Fig. 2 it can be seen that, Rainfall (1) ranges from 1324-1486mm per annum, averaging about $1405 \mathrm{~mm}$. The areas bordering the FCT are those with high rainfall (1420-1486mm) as compare to the other parts. The drainage density (2) ranges from $0-322 \mathrm{~km}^{2}$. High density $\left(227-322 \mathrm{~km}^{2}\right)$ occurs in linear fusion along Tafa and Gauraka axis. Furthermore, Sandy (3) soil lies predominantly to the north, and spread towards northeast and northwest, while the south and the central parts and some portion of the northwestern margin is covered with loamy soil. The west and the southeast are mainly covered with clay soil. Furthermore, the elevation of Suleja (4) ranges from $279-556 \mathrm{~m}$ above sea level. Thus, to the north, the study area is predominantly a highland which descends towards the south and western parts. Also the area is dominated by steep gradient descent towards the extreme west and southwestern sides of the region, with the slope (5) ranges between 0 $80 \%$. However, from the LULC (6) features of the area most of the development is on the one part of 
the city along the river course and the western route in a linear synthesis. There is also concentration in the south and some dispersal across the study area. Settlements like: Fadaman-abuchi, Bamburu, Zariyawa, Gajiri, Numba, Chaza and Gwazunu are heavily farming oriented (Aminu et al., 2013), hence, the abundant farmland (Fig. 2).

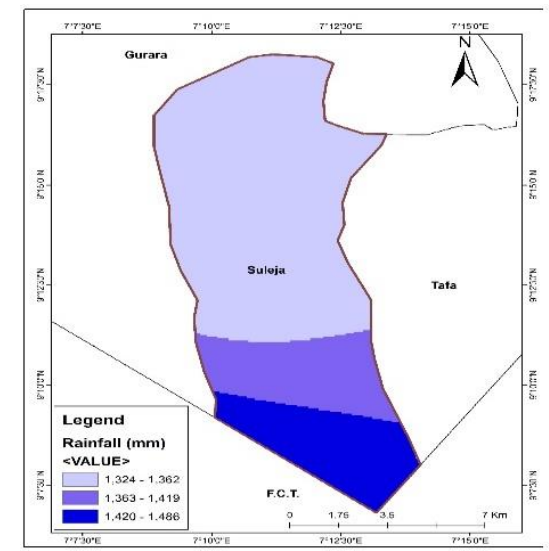

Rainfall Distribution (1)

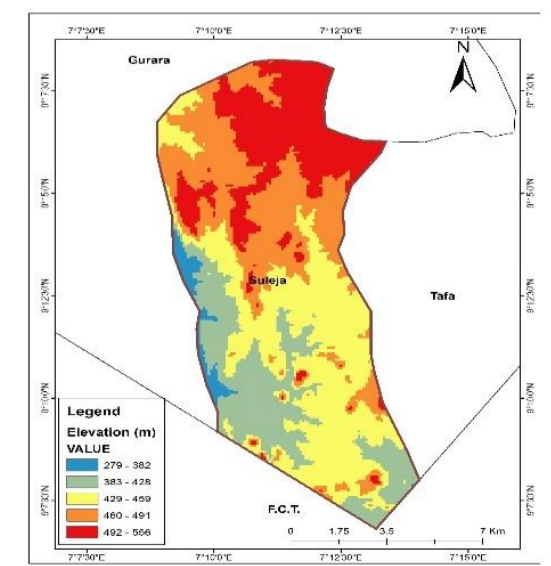

Elevation (4)

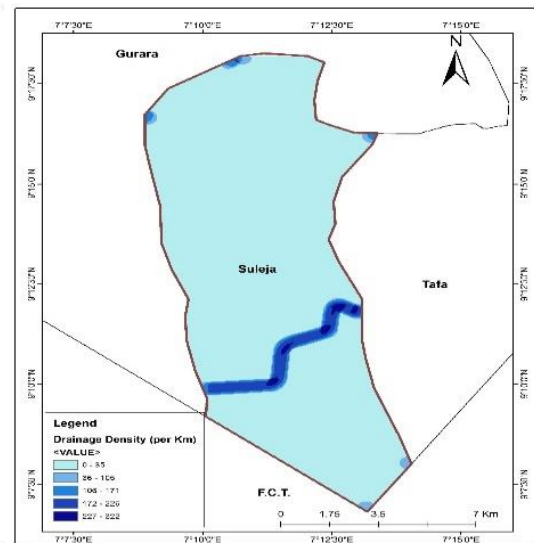

Drainage Density (2)
Fig. 2 represents the characteristics of flood risk factors in the study area.

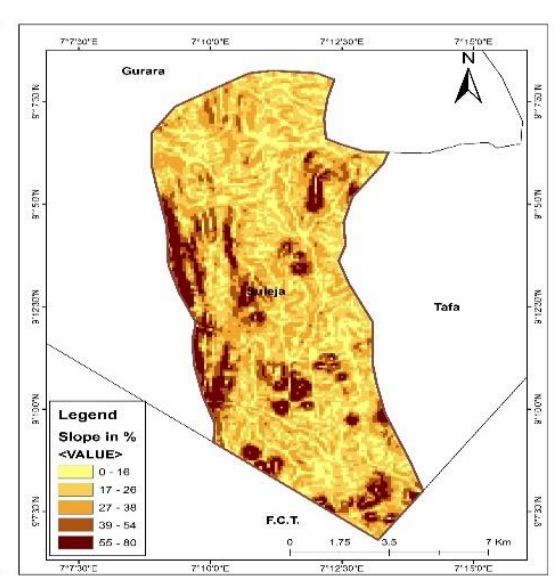

Slope (5)

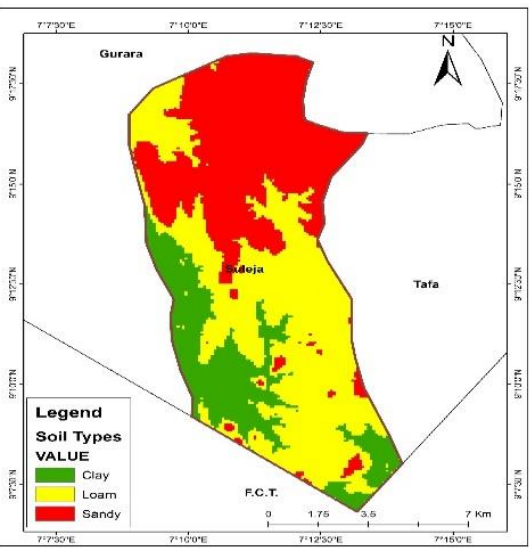

Soil Classification (3)

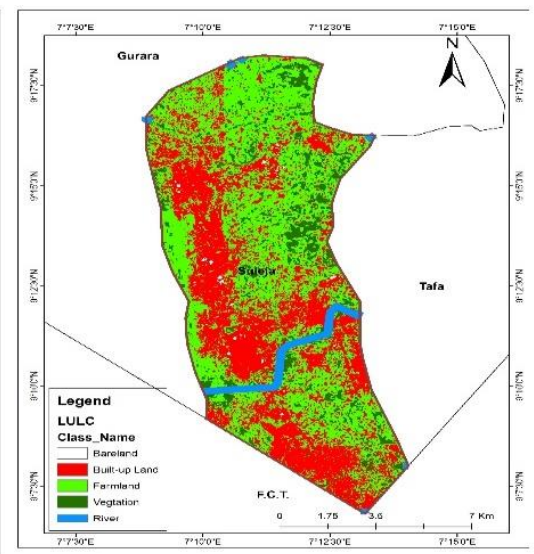

LULC Structure (6)

Figure 2: Characteristics of Flood Risk Factors (Source: Source: Author's GIS Analysis, 2019)

\subsection{Pair-wise Comparison for Flood Risk Factors in Suleja}

The pair-wise comparison done for areas with high rainfall against those with low had the ratio of 9/7 indicating that high rainfall rated 9 , have extreme influence on flood over those low and moderate (5). This procedure is repeated for all the classes against each other. It was also revealed that, areas with very high drainage densities rated 7 , have very strong influence over the rest of the classes. Further, clay soils are designated as being poorly drained while, loamy and sandy are considered moderately and well drained respectively (UNCHS-Habitat, 2001). Comparison done that, sandy rated 9 have extreme influence over clay and loamy in that order. Likewise, areas with very high elevation (9) contribute more to flood in the area, as it facilitate surface water run-off. Similarly, very low slope (9/7), was found to have the greatest influence against those with low, moderate, high and very high slopes respectively. Similarly, built-up areas (9) also contribute more over the rest of the LULC feature classes. Thus, built-up land and cemented surfaces generate more surface runoff since they do not allow water infiltration, while others like vegetation permit interception, thereby reducing the runoff and consequently the flood magnitude (Lindsay-Walters, 2015). Further analysis from Fig. 3 corroborated that, high rainfall, very high drainage densities, 
poorly drained soil, very low elevation, slope and built up land weighed 38, 32, 74, 51, 47 and
51 respectively, contributes to flood in the study area.

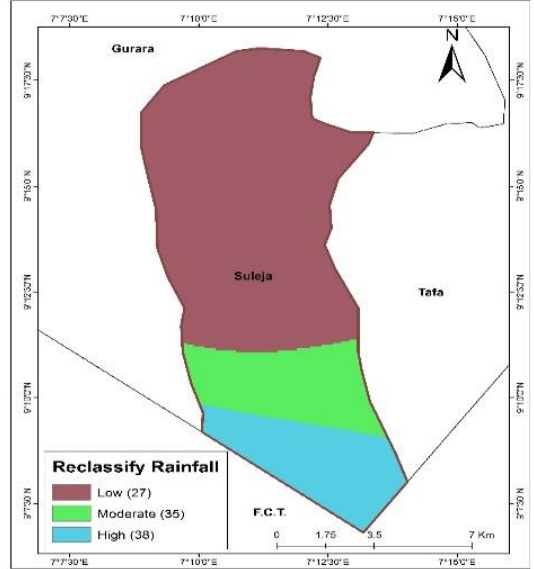

Re-classified Rainfall (1)

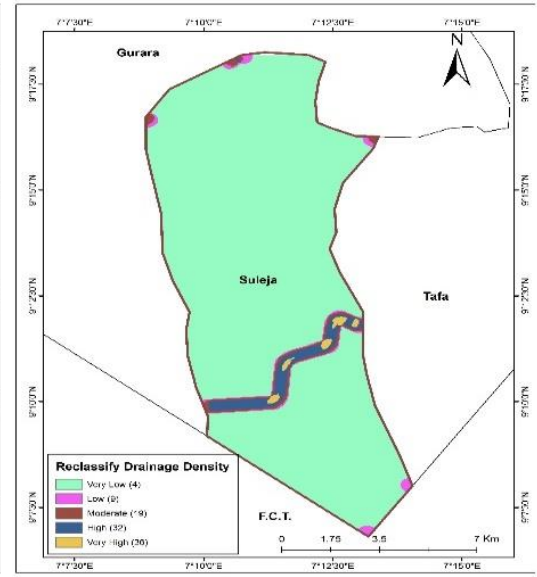

Re-classified drainage (2)

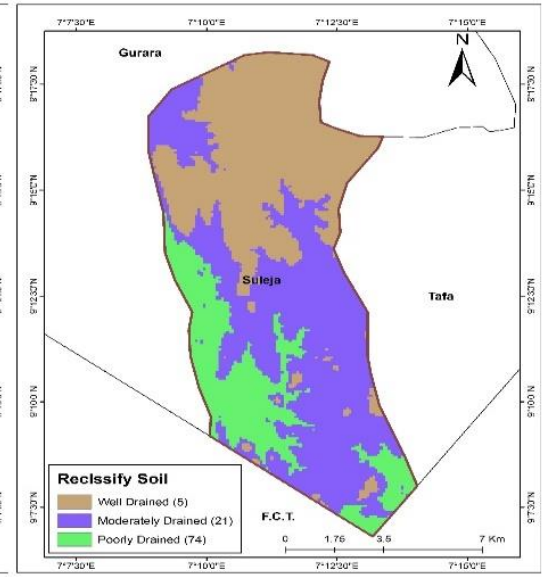

Re-classified soil (3)

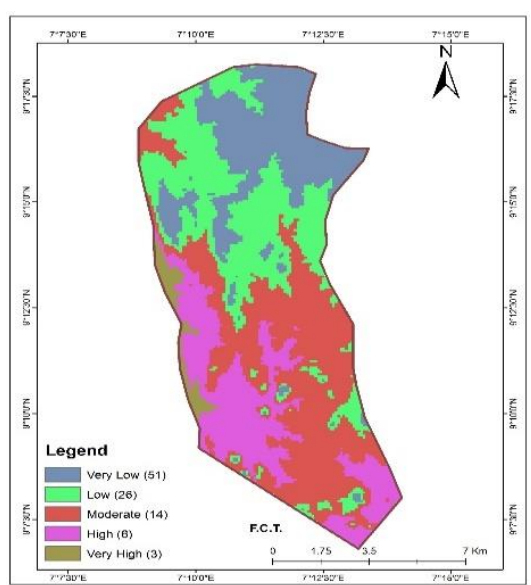

Re-classified elevation (4)

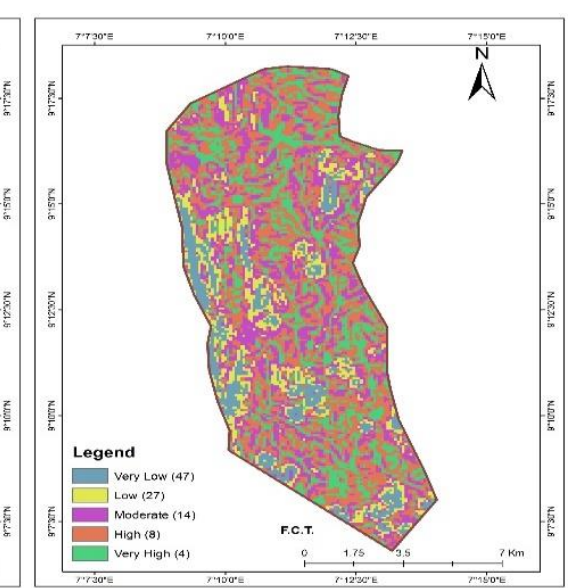

Re-classified slope (5)

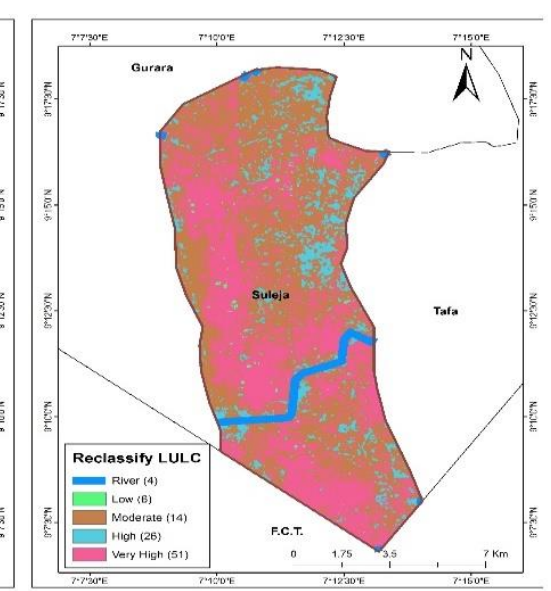

Re-classified LULC (6)

Figure 3: Reclassified Flood Risk Factors Based on the Weights Generated using the AHP (Source: Source: Author's GIS Analysis, 2019)

\subsection{Flood vulnerability Zone in Suleja}

This section presents the result of overlay operation based on the pair-wise comparison carried out for the flood risk factors (Table 3), and the flood vulnerability map (Fig. 4).

Table 3: Weight for Flood Risk Factors

\begin{tabular}{lrrrrrrr}
\hline Factors & Rainfall & Slope & Elevation & $\begin{array}{c}\text { Drainage } \\
\text { Density }\end{array}$ & LULC & Soil & Weight \\
\hline Rainfall & 1 & 3 & 3 & 7 & 9 & 1 & 34 \\
Slope & $1 / 3$ & 1 & 3 & 5 & 7 & 9 & 31 \\
Elevation & $1 / 3$ & $1 / 3$ & 1 & 3 & 5 & 7 & 18 \\
Drainage density & $1 / 7$ & $1 / 5$ & $1 / 3$ & 1 & 3 & 5 & 9 \\
LULC & $1 / 9$ & $1 / 7$ & $1 / 5$ & $1 / 3$ & 1 & 3 & 5 \\
Soil & 1 & $1 / 9$ & $1 / 7$ & $1 / 5$ & $1 / 3$ & 1 & 4 \\
\hline
\end{tabular}

Consistency Ratio= 0.05

(Source: Author's GIS Analysis, 2019) 


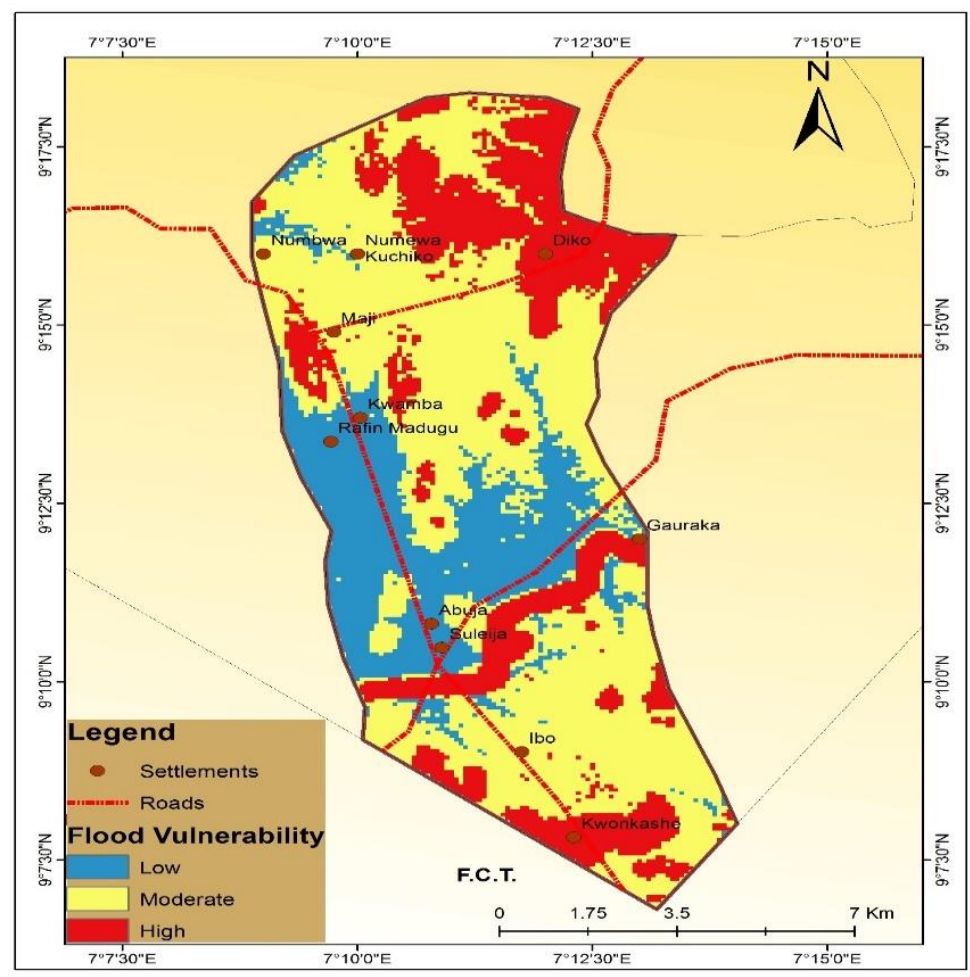

Figure 4: Flood Vulnerability Map of Suleja (Source: Author's GIS Analysis, 2019)

The weights generated reveal that rainfall and slope, weighted 34 and 31, have the greatest influence on flood occurrences in the study area. Elevation, drainage density, land used and soil on the other hand contribute to the flood incidence in that order. This implies that, flood in Suleja occur at the event of rainfall. Its intensity, duration and amount are generally believed to be the principal factors in most flood events in the tropics which are partly or wholly climatological in nature (Muhammad, 2015). The significant findings showed a CR value of 0.05 , which fell much below the threshold value of 0.1 and it indicated a high level of consistency. Hence, it was concluded that rainfall and slope have the highest influence on flood within the study area. The flood vulnerability map reveals that areas of high vulnerability constitute $37 \%$ of the study area while moderate and low vulnerable areas constitute $45 \%$ and $18 \%$ respectively. Elements at high risk of flood in the study area are those found at the extreme northeast, where elevation is very low, southwest where rainfall distribution is high and on low lying areas along the rivers or depressions. Most of the properties situated within these areas are built-up areas consisting of residential areas, commercial structures, roads and farmlands. Settlements that are more vulnerable include: Diko, Numewa, Kuchiko, Maji, Gauraka and Kwonkashe.

\section{Conclusion and Recommendations}

The findings show that areas that lie along the rivers and on low elevations are more prone to flood at rainfall events than those on higher elevations. It therefore means cultural features such as residential, commercial, educational and health facilities amongst others as well as the populace found within these areas are at great risk of flood. The risk of contracting water-borne diseases such as cholera as a result of the devastation cause by the flood to their sanitation and immediate surroundings might be a side effect. However, the deficiencies particularly of institutional capacities to implement risk reduction measures through public early warning system, may shed light on the risk context of the area and how vulnerability is complicated by increasing exposure to risks. If menace flooding of Suleja is continually ignored, the risk of exposure to flood will be on the increase and more properties, farmlands and crops, public infrastructures and lives may continue to be lost in due course. Therefore using the Geo-hazard map as a guide, local councils and other stakeholders can act to prepare for potential floods, also to proactively promote an appropriate land-use policy that will minimize threat to lives due to flood. 


\section{References}

Aminu, Z., Yakubu, M., Mohammed, A.A. and Niranjan, K. (2013): Impact of Land Use on Soil Quality in Suleja, Niger State. Indian Journal of Science, Vol. 2(2):1-7.

Anderson, J.R., Hardy, E.E., Roach, J.T. and Witner, R.E. (2001): Landuse and Landcover Classification System for use with Remote Sensor Data. Geological Survey Professional Paper 964, Presented in United State Geological Survey Circular 671. Washington: United State Government Printing Office.

APFM, (2012): Urban Flood Risk Management: A Tool for Integrated Flood Management. Associated Programme on Flood Management. World Meteorological Organization 2012, Vol. 29, Pp. 1-43.

Chang, N.-B.; Guo, D.-H. (2006): Urban flash flood monitoring, mapping and forecasting via tailored sensor network system. In Proceedings of the IEEE International Conference on Networking, Sensing and Control, (ICNSC'06), Ft. Lauderdale, FL, USA, 23-25 April 2006.

Emmanuel, A.O., Olawumi, O.R. and Durojaye, E. (2012): An assessment of flood hazard in Nigeria: The case of mile 12, Lagos. Mediterranean Journal of Social Sciences. Vol. 3(2): Pp. 367-375 May 2012

Few, R., Ahern, M., Matthies, F. and Kovats, S. (2004): Floods, health and climate change: a strategic review. Tyndall Centre for Climate Change Research, 2004, (63).

Lindsay-Walters, A. (2015): The chances of a river flooding after a period of rain are determined by natural factors. Downloaded from www.markedbyteachers.com on $18^{\text {th }}$ January, 2015

Niger State Bureau of Statistics (2011): Facts and Figures on Niger State. Niger State Planning Commission. Statistical Year Book. 2011 Edition

Niger State Emergency Management Agency, (2018): Flood in Niger State: Death toll rises to 40, 100 communities now submerged. In Vanguard dated September 15, 2018

NPC, (2006). Population and housing census of the federal republic of Nigeria: National and state population and housing priority tables. Population Commission Office, Niger state.

Ozcan, O. and Musaoglu, N. (2010): Vulnerability Analysis of Flood in Urban Areas Using Remote Sensing and GIS. In Proceedings of the 30th EARSeL Symposium: Remote Sensing for Science, Education and Culture, Paris, France, 31 May-3 June 2010.

Saaty, T. (1980): The Analytical Hierachy Process. New York: McGraw Hill.
UNISDR, (2015): “Hyogo Framework for Action 2015-2030: Building the Resilience of Nations and Communities to Disasters". United Nations International Strategy for Disaster Reduction World Conference on Disaster Reduction. Pp.16-32, Sendai Framework, Japan Reduction Education

Wisner, B., Blaikie, P., Cannon, T., and, Davies, I. (2012): At Risk Natural Hazard, People's Vulnerability and disasters. Routledge: New York

Yahaya, S., Ahmad, N. and Abdalla, R.F. (2010): Multi-criteria Analysis for Flood Vulnerable Areas in Hadejia-Jama'are River Basin, Nigeria. European Journal of Scientific Research. Vol. 42 No. 1. pp. 71-83.

Yalcin, G. and Akyurek, Z. (2004): Analyzing Flood Vulnerable Areas with Multi-criteria Evaluation. 20th ISPRS Congress, Istanbul, Turkey. 